\title{
Utilization of earth observation technology for mapping spatio-temporal changes of urban water bodies (ponds) and its environmental impacts in Hadejia, Nigeria
}

\begin{abstract}
Ponds locally called (Kududfi in Hausa) are either naturally or artificially created ditches which usually contained water and constitute significant elements of the settlement in Northern Nigeria which can be expanded beyond their natural depth. Many ponds in the urban centers of developing nations have inlets and outlets for transporting water from small ponds to large ones especially ponds that serve as reservoir for the domestic and rain water storage. Earth observation technology allowed researchers to accurately study the past, current and even predict the future of spatial temporal changes of urban environment including the water bodies (ponds). In developing nations like Nigeria many ancientsôcities became over crowded, this is likely because of their history, opportunities or economic advantages. Nevertheless, many of the ancientố cities in Africa experienced regular annual urban flood that make the city centers as water logging throughout the wet season due to community culture toward destructions and claiming ownership of water bodies (ponds) either by government officials or individuals which normally serve as a domestic and rain water reservoir. Therefore, this research aimed on the utilization of geospatial technologies for mapping spatial temporal changes of urban water bodies (ponds) and its environment impacts in the study. Research also designed to map the geospatial distribution of ponds (urban water bodies) and how does human activities affect its functions. The satellite image data acquired for years 1999 and 2019 respectively. Nevertheless, the imageries were geometric and radiometric corrected using the quick atmospheric correction (QUAC). The findings indicated that most of the Ponds changed in their size, shape and mainly filled with solid waste. From the analysis of the research shown that annual urban flood is attributed from the destructions of ponds. Changes from other land use types also affect the water bodies such as schools, residential, commercial, etc. the findings also showed the impacts of ponds destructions such as making areas water logged, occurrence of urban flood, change in local climate and alteration of hydro-geomorphic nature of the area.
\end{abstract}

Keyword: Environment; GIS; Monitoring; Remote sensing; Urban hydrology 